\title{
Jenis Serangga Hama Pada Tanaman Cengkeh (Syzygium aromaticum) di Desa Salumpaga Kecamatan Tolitoli Utara Kabupaten Tolitoli
}

\author{
${ }^{1}$ Nuraini, ${ }^{2}$ Sukmawati, ${ }^{3}$ Manap Trianto \\ Fakultas Biologi, Universitas Gadjah Mada, Yogyakarta, Indonesia \\ 1aini77785@mail.ugm.ac.id, ${ }^{2}$ sukmawati96@mail.ugm.ac.id, ${ }^{3}$ manaptrianto@mail.ugm.ac.id
}

\section{ARTICLE INFO}

\section{Article History:}

Received : 07-03-2019

Revised : 11-05-2019

Accepted : 17-05-2019

Online : 30-05-2019

Keywords:

Pest Insect; Syzygium aromaticum; Desa

Salumpaga; Kecamatan

Tolitoli; Kabupaten

Tolitoli

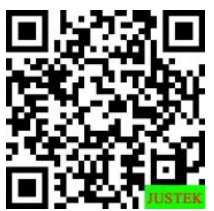

\begin{abstract}
Abstract: Cloves (Syzygium aromaticum) are native to Indonesia which have high social and economic value, however cloves also have different types of pests. The latest information on insect pests in cloves is still very limited. This study aims to describe the types of insect pests found in clove (Syzygium aromaticum). This type of research is a descriptive exploratory research. Pest insect samples were taken at 3 observation locations, namely at a slope of $0 \%$, a slope of $<15 \%$ and a slope of $>15 \%$ and identification of the pests found. The results showed that at a $0 \%$ slope, the insect pests found were Coptotermes gestroi and Coptocercus biguttatus. At a slope of $<15 \%$, the insect pests found were Coptotermes gestroi, Hexamitodera semivelutina and Coptocercus biguttatus. Whereas at a slope of $15 \%$, the insect pests found were Coptotermes gestroi, Hexamitodera semivelutina, Coptocercus biguttatus and Nothopeus sp.
\end{abstract}

\begin{abstract}
Abstrak: Cengkeh (Syzygium aromaticum) merupakan tanaman asli Indonesia yang memiliki nilai sosial dan ekonomi yang tinggi, akan tetapi cengkeh juga memiliki jenis hama yang berbeda. Informasi terbaru tentang serangga hama pada cengkeh masih sangat terbatas. Penelitian ini bertujuan untuk mendeskripsikan jenis-jenis serangga hama yang terdapat pada tanaman cengkeh (Syzygium aromaticum). Jenis Penelitian adalah penelitian deskriptif eksploratif. Pengambilan sampel serangga hama dilakukan pada 3 lokasi pengamatan yakni pada kemiringan 0\%, kemiringan $<15 \%$ dan kemiringan $>15 \%$ serta dilakukan identifikasi pada seragga hama yang ditemukan. Hasil penelitian menunjukkan pada kemiringan 0\%, serangga hama yang ditemukan yaitu Coptotermes gestroi dan Coptocercus biguttatus. Pada kemiringan $<15 \%$, serangga hama yang ditemukan yaitu Coptotermes gestroi, Hexamitodera semivelutina dan Coptocercus biguttatus. Sedangkan pada kemiringan $>15 \%$, serangga hama yang ditemukan yaitu Coptotermes gestroi, Hexamitodera semivelutina, Coptocercus biguttatus serta Nothopeus sp.
\end{abstract}

\section{A. LATAR BELAKANG}

Cengkeh (Syzygium aromaticum) adalah tanaman yang berasal dari Kepulauan Maluku serta merupakan salah satu tanaman asli Indonesia yang dimanfaatkan atau dikembangkan sebagai komoditas penting dalam mendukung sektor industri khususnya sebagai salah satu sumber ekonomi masyarakat (Nuraini et al., 2020; Sukmawati et al., 2020). Selain dimanfaatkan sebagai bahan rempah-rempah, tanaman ini juga 
dimanfaatkan sebagai bahan obat (radang, sakit gigi, pernapasan, serta jantung), bahan rokok kretek, pengawet berbagai jenis makanan, biopestisida, dan parfum (Suprianto et al., 2020; Trianto dan Marisa, 2020; Trianto et al., 2020).

Berdasarkan data yang ada, kebutuhan cengkeh di Indonesia sekitar 120 ribu ton dalam tahunnya. Akan tetapi, tingginya kebutuhan cengkeh tidak berbanding lurus dengan tingkat produksinya yang hanya memenuhi sekitar 80 ribu ton dalam setahun (Dinas Perkebunan Jawa Timur, 2012). Di lapangan jumlah produksi cengkeh dipengaruhi oleh beberapa faktor salah satunya yaitu keberadaan serangga hama. Serangga hama merupakan salah satu organisme yang dapat menurunkan produksi cengkeh pada suatu wilayah. Serangan hama yang telah terjadi, baik pada areal pembibitan atau perkebunan skala besar dapat menyebabkan perlambatan proses pertumbuhan bahkan menyebabkan kematian pada tanaman cengkeh. Terhambatnya pertumbuhan tanaman cengkeh mengakibatkan rendahnya produksi baik secara kualitas maupun kuantitas. Penurunan produksi cengkeh yang diakibat oleh serangan hama dapat mencapai 10\% sampai 25\% (Indriati, 2007; Trianto et al., 2020).

Hingga saat ini informasi tentang jenis hama pada tanaman cengkeh di Tolitoli masih sangat kurang, khususnya di Desa Salumpaga. Padahal secara tidak langsung, informasi tentang penyebaran hama cengkeh di areal perkebunan dapat menjadi gambaran bagi para petani dalam proses melakukan pengendalian serta pengelolaan hama. Penelitian ini bertujuan untuk memberikan informasi terkait jenis serangga hama pada tanaman cengkeh (Syzygium aromaticum) di Desa Salumpaga, Kecamatan Tolitoli, Kabupaten Tolitoli.

\section{B. METODE PENELITIAN}

Penelitian ini bersifat deskriptif eksploratif. Penelitian ditujukan untuk mendeskripsikan fenomena-fenomena yang ada. Alat yang digunakan pada penelitian ini yaitu kamera, alat tulis, buku identifikasi, kertas label, plastik sampel, termometer, anemometer, mistar dan hygrometer. Adapun bahan yang digunakan dalam penelitian ini yaitu specimen serangga hama dan alkohol 70\%.

Pengambilan sampel hama dilakukan dengan teknik jelajah dengan menggunakan metode purposive sampling yang diartikan sebagai teknik untuk menentukan sampel penelitian dengan beberapa pertimbangan tertentu seperti lokasi penelitian. Adapun tahap pengambilan sampel, pengamatan dan pengidentifiksian yaitu menentukan luas wilayah penelitian yaitu $14.800 \mathrm{~km}$, melakukan pengukuran kemiringan tanah dengan menggunakan aplikasi clinometer, melakukan pengukuran parameter lingkungan seperti suhu, kelembaban dan kecepatanangin, melakukan proses pencuplikan sampel penelitian dengan menjelajahi lokasi tempat penelitian yang terdiri dari dataran dan kemiringan $0 \%,>15 \%$ serta $<15 \%$, mengkoleksi hewan sampel yang ditemukan pada setiap tanaman cengkeh selama proses jelajah dengan cara memasukkan hewan kedalam plastik sampel yang telah berisia lkohol 70\% dan diberi label, mengambil gambar jenis serangga yang di dapatkan dan mengidentifikasi serangga tersebut, mengamati dan memasukan pada lembar penelitian, serta melakukan proses pengidentifikasian yang dilakukan di lokasi penelitian. 


\section{HASIL DAN PEMBAHASAN}

Berdasarkan hasil penelitian pada kawasan perkebunan tanaman cengkeh di Desa Salumpaga, maka lokasi penelitian dibagi menjadi 3 tingkat kemiringan, adapun pembagian dari 3 tingkat kemiringan tersebut berdasarkan kondisi areal setempat, yang masing-masing tingkat kemiringan $0 \%$, tingkat kemiringan $<15 \%$, dan tingkat kemiringan $>15 \%$. Selanjutnya, berdasarkan hasil pengukuran kondisi fisik lingkungan yang telah dilakukan, yang meliputi keadaan suhu, kelembaban dan kecepatan angin pada setiap tingkat kemiringan tanah, diperoleh data kondisi fisik lingkungan yang menunjukan variasi perbedaan pada tiap tingkat kemiringan tanah di pegunungan desa Salumpaga. Data sebagai berikut disajikan dalam Tabel 1.

Tabel 1. Data kondisi fisik lingkungan pada tiap kontur kemiringan

\begin{tabular}{lclc}
\hline No & Kemiringan & \multicolumn{1}{c}{ Parameter } & Kondisi fisik lingkungan \\
\hline 1. & $0 \%$ & Suhu Udara $\left({ }^{\circ} \mathrm{C}\right)$ & $28{ }^{\circ} \mathrm{C}$ \\
\cline { 3 - 4 } & & Kelembaban $(\%)$ & $86,0 \%$ \\
\cline { 3 - 4 } & & Kecepatan Angin $(\mathrm{km} / \mathrm{jam})$ & $2,0 \mathrm{~km} / \mathrm{jam}$ \\
\hline 2. & $>15 \%$ & Suhu Udara $\left({ }^{\circ} \mathrm{C}\right)$ & $28{ }^{\circ} \mathrm{C}$ \\
\cline { 3 - 4 } & & Kelembaban $(\%)$ & $86,1 \%$ \\
\cline { 3 - 4 } & & Kecepatan Angin $(\mathrm{km} / \mathrm{jam})$ & $1,8 \mathrm{~km} / \mathrm{jam}$ \\
\hline 3. & $<15 \%$ & Suhu Udara $\left({ }^{\circ} \mathrm{C}\right)$ & $27{ }^{\circ} \mathrm{C}$ \\
\cline { 3 - 4 } & & Kelembaban $(\%)$ & $80,0 \%$ \\
\cline { 3 - 4 } & & Kecepatan Angin $(\mathrm{km} / \mathrm{jam})$ & $2,1 \mathrm{~km} / \mathrm{jam}$ \\
\hline
\end{tabular}

Hasil yang diperoleh dari ketiga tingkat kemiringan penelitian sangat bervariasi, dimana pada kemiringan $0 \%$ serangga hama yang diperoleh sebanyak 2 jenis. Sedangkan pada kemiringan $<15 \%$ diperoleh 3 jenis serangga hama dan pada kemiringan $>15 \%$ diperoleh 4 jenis serangga hama dimana 3 jenis serangga hama termasuk dalam 1 family (Tabel 2).

Tabel 2. Jenis-jenis serangga hama yang ditemukan di Desa Salumpaga

\begin{tabular}{llllccc}
\hline \multirow{2}{*}{ No } & \multirow{2}{*}{ Ordo } & Familia & \multicolumn{2}{c}{ Spesies } & \multicolumn{2}{c}{ Jumlah } \\
\cline { 5 - 7 } & & & $\mathbf{0 \%}$ & $<\mathbf{1 5 \%}$ & $\mathbf{1 5 \%}$ \\
\hline 1 & Coleoptera & Cerambycidae & Hexsamitodera semivelutina & - & 1 & 6 \\
2 & Coleoptera & Cerambycidae & Coptocercus biguttatus & 2 & 6 & 3 \\
3 & Isoptera & Rhinotermitidae & Coptotermes gestroi & 54 & 66 & 73 \\
4 & Coleoptera & Cerambycidae & Nothopeus sp. & - & - & 1 \\
\hline
\end{tabular}

Serangga dianggap sebagai hama ketika keberadaannya merugikan kesejahteraan manusia, estetika suatu produk atau kehilangan hasil panen. Apabila pengertian hama itu hewan yang merugikan, maka serangga hama didefinisikan sebagai serangga yang menganggu dan atau merusak tanaman baik secara ekonomis atau estetis (Untung dan Sudomo, 1997; Dirham dan Trianto, 2020; Hartina dan Trianto, 2020). 
Berdasarkan hasil dan identifikasi pada kemiringan 0\% yang ditempatkan pada daerah dataran, serangga hama diperoleh sebanyak 2 jenis yaitu Coptotermes gestroi yang berjumlah 54 individu dan Coptocercus biguttatus berjumlah 2 individu. Selain itu dilakukan pengukuran kondisi fisik lingkungan seperti suhu udara $28{ }^{\circ} \mathrm{C}$, kelembaban $86,0 \%$ dan kecepatan angin 2,0 km/jam.

Pada kemiringan $<15 \%$, serangga hama yang ditemukan sebanyak 3 jenis yaitu Coptotermes gestroi berjumlah 66 individu, Hexamitodera semivelutina 1 individu dan Coptocercus biguttatus berjumlah 6 individu. Selain itu dilakukan pengukuran kondisi fisik lingkungan seperti suhu udara $28{ }^{\circ} \mathrm{C}$, kelembaban $86,1 \%$ dan kecepatan angin 1,8 $\mathrm{km} / \mathrm{jam}$.

Sedangkan pada kemiringan $>15 \%$, serangga hama yang ditemukan sebanyak 4 jenis yaitu Coptotermes gestroi yang berjumlah 73 individu, Hexamitodera semivelutina 6 individu, Coptocercus biguttatus 3 individu serta Nothopeus sp 1 individu. Selain itu dilakukan pengukuran kondisi fisik lingkungan seperti suhu udara $27{ }^{\circ} \mathrm{C}$, kelembaban $80,0 \%$ dan kecepatan angin 2,1 km/jam.

Penyebaran pada lokasi pengambilan sampel dari 4 jenis serangga hama ini tidak merata, hal tersebut dipengaruhi oleh beberapa faktor diantaranya faktor dalam yang menentukan tinggi rendahnya populasi serangga dan faktor luar seperti keadaan fisik lingkungan (suhu, kelembaban dan kecepatan angin).

Suhu merupakan parameter yang paling penting dalam mengatur organisme, karena suhu dapat berperan dalam perkembangan dan pertumbuhan serangga. Dari hasil pengukuran suhu pada pegunungan di Desa Salumpaga diperoleh suhu rata-rata berkisar $27,66{ }^{\circ} \mathrm{C}$ suhu tersebut masi dalam keadaan yang normal. Menurut Campbell (2003) suhu optimum bagi kebanyakan serangga adalah sekitar $25^{\circ} \mathrm{C}$. Pada umumnya serangga lebih tahan terhadap keadaan yang lembab, bahkan beberapa jenis serangga menyukait empat yang lembab.

Kelembaban udara mempengaruhi kehidupan serangga, kelembaban yang dimaksut adalah kelembaban udara dan tempat hidup serangga dimana merupakan factor penting yang mempengaruhi distribusi, kegiatan dan perkembangan serangga. Dalam kelembaban yang sesuai, serangga biasanya lebih tahan terhadap suhu ekstrim. Pada umumnya serangga lebih tahan terhadap terlalu banyak air, akan tetapi, jika kebanyakan air seperti banjir dan hujan deras merupakan bahaya bagi beberapa jenis serangga (Jumar, 2000). Dari hasil pengukuran parameter lingkungan pada pegunungan di Desa Salumpaga diperoleh kelembaban rata-rata berkisar 84,0 \%.

Angin dapat berpengaruh secara langsung terhadap kelembaban dan proses penguapan badan serangga dan juga berperan besar dalam penyebaran suatu serangga dari tempat yang satu ketempat yang lainnya. Dari hasil pengukuran parameter lingkungan pada pegunungan di Desa Salumpaga diperoleh kecepatan angin rata-rata berkisar $1,97 \mathrm{~km} / \mathrm{jam}$

Ada beberapa contoh sumber pembelajaran yang dapat diterapkan dalam proses belajar, salah satu contoh sumber pembelajaran yang ada disekitar kita adalah lingkungan. Lingkungan adalah segala sesuatu baik yang berupa benda hidup maupun 
mati yang terdapat disekitar tempat tinggal kita maupun disekolah. Lingkungan kita menyimpan berbagai jenis sumber dan media pembelajaran yang tidak terbatas.

Kawasan pegunungan desa Salumpaga sangat berpotensi untuk dijadikan sebagai sumber dan media pembelajaran dan dimanfaatkan sebagai kawasan penelitian berbagai kalangan baik dari lembaga-lembaga kajian lingkungan maupun akademik. Kawasan pegunungan desa Salumpaga menyimpan berbagai jenis serangga hama serta spesies hewan lainnya.

\section{SIMPULAN DAN SARAN}

Serangga pengunjung pada spesies bunga anggrek Vanda tricolor terdiri atas 12 genus dengan komposisi yaitu di luar green house (Crematogaste, Anoplolepis, Xylocopa, Vespa, Drosophila, Stomorhina, Lucilia, Chrysomya, Musca, Camptomyia, Orchestes, Carpophilus, Stagmomantis, dan Ligocoris) dan di dalam green house (Aphaenogaster dan Anoplolepis). Berdasarkan hasil penilitian, pada kawasan pegunungan desa Salumpaga dapat ditarik kesimpulan yaitu jenis serangga hama di kawasan pegunungan desa Salumpaga sebanyak 4 jenis. Jenis serangga hama yang ditemukan pada tiap-tiap kemiringan yaitu pada kemiringan 0\% serangga hama yang ditemukan yaitu Coptotermes gestroi dan Coptocercus biguttatus. Pada kemiringan $<15 \%$, serangga hama yang ditemukan yaitu Coptotermes gestroi, Hexamitodera semivelutina dan Coptocercus biguttatus. Sedangkan pada kemiringan $>15 \%$, serangga hama yang ditemukan yaitu Coptotermes gestroi, Hexamitodera semivelutina, Coptocercus biguttatus serta Nothopeus sp.

Sebaiknya dilakukan sosialisasi kemasyarakat sekitar lokasi penelitian terkait betapa pentingnya pengetahuan mengenai serangga hama yang dapat merugikan tanaman cengkeh pada kawasan pegunungan di Desa Salumpaga.

\section{REFERENSI}

Campbell. (2003). Biologi : Edisi Kelima Jilid 2. Jakarta: Erlangga.

Dinas Perkebunan Jawa Timur. (2012). Produksi kurang, impor ccengkeh butuh 40 ribu ton. [internet], [diunduh 06 april 2017]. Tersedia www.disbunjatim.go.id/doc

Dirham, dan Trianto, M. (2020). Analisis Isi Lambung Ikan Mujair (Oreochromis mossambicus) di Perairan Danau Talaga Kabupaten Donggala. Jurnal BIO-EDU, 5(3), 118-128.

Hartina, S, dan Trianto, M. (2020). Keanekaragaman Zooplankton di Perairan Danau Lindu Provinsi Sulawesi Tengah. Jurnal BIO-EDU, 5(3), 129-139.

Indriati. (2007). Pengendalian hama terpadu hama penggerek cengkeh - Sinar tani. Bogor: Rubrik agroinovasi.

Jumar. (2000). Entomologi Pertanian. Jakarta: PT. Rineka Cipta

Nuraini, Trianto, M, Sukmawati, dan Marisa, F. (2020). Keanekaragaman Sumber Pakan dan Perilaku Mencari Pakan Lebah Tetragonula laeviceps (Hymenoptera: Meliponini) di Kecamatan Parigi Selatan. Jurnal BIO-EDU, 5(3), 173-184.

Sukmawati, Trianto, M, dan Nuraini. Hubungan Kekerabatan Intraspesies Tanaman Puring (Codiaeum variegatum L.) di Kecamatan Parigi Selatan Berdasarkan Analisis Fenetik. Jurnal BIO-EDU, 5(3), 161-172. 
Suprianto, Trianto, M, Alam, N, dan Kirana, N. G. A. G. C. (2020). Karakter morfologi dan analisis daerah conserved gen elongation factor 1a (EF1a) pada Lepidotrigona terminata. Jurnal Metamorfosa, 7(2), 30-39.

Trianto, M, dan Marisa, F. (2020). Diversity of Bees and Wasp (Hymenoptera) in Cowpea (Vigna sinensis L.) in Agricultural Area at Martapura District, Banjar Regency, South Kalimantan. Journal of Science and Technology, 9(2), 29-33.

Trianto, M, dan Marisa, F. (2020). Studi Kelimpahan dan Pola Sebaran Collembola pada Tiga Tipe Penggunaan Lahan di Kabupaten Banjar, Kalimantan Selatan. Jurnal BIO-EDU, 5(3), 107-117.

Trianto, M, Kaini, Saliyem, Warsih, E, dan Winarsih. (2020). Keanekaragaman Serangga Polinator pada Tanaman Nanas (Ananas comosus (L.) Merr.) di Desa Bincau. Jurnal Penelitian Science dan Pendidikan, 9(2), 154-162.

Trianto, M, Marisa, F, dan Siswandari, N.P. (2020). Kelimpahan Nisbi, Frekuensi, dan Dominansi Jenis Lalat di Beberapa Pasar Tradisional di Kecamatan Martapura. Jurnal Metamorfosa, 7(2), 21-29.

Trianto, M, Marisa, F, dan Sukmawati. (2020). Keanekaragaman Jenis Rayap pada Perkebunan Kelapa Sawit dan Perkebunan Karet di Kabupaten Banjar, Kalimantan Selatan. Jurnal Biologi Makassar, 5(2), 199-209.

Untung, K, dan Sudomo, M. (1997). Pengelolaan Serangga Secara Berkelanjutan. Makalah disampaikan pada symposium Entomologi, Bandung. 